\title{
A Retrospective Analysis on the Cystic Echinococcosis Cases Occured in Northeastern Punjab Province, Pakistan
}

\author{
Aisha Khan', Sarmad Zahoor', Haroon Ahmed', Uzma Malik², Rabia Amin Butt³, Muhammad Sultanul Muzam³, \\ Seyma Gunyakti Kilinc ${ }^{4}$, Noorulain Noor ${ }^{3}$, Saroosh Zahoor ${ }^{5}$, Muhammad Sohail Afzal ${ }^{5}$, Hamza Mansur ${ }^{6}$, \\ Shumaila Irum ${ }^{7}$, Sami Simsek ${ }^{4, *}$ \\ 'Department of Biosciences, COMSATS University Islamabad (CUI), Park Road, Chakh Shahzad, Islamabad, Pakistan; ${ }^{2}$ Mayo Hospital Lahore, \\ Pakistan; ' ${ }^{3}$ epartment of Pathology, Chughtai Laboratory, Lahore, Pakistan; ${ }^{4}$ Department of Parasitology, Faculty of Veterinary Medicine, University \\ of Firat, 23119, Elazig, Turkey; ${ }^{5}$ Department of Life Sciences, University of Management and Technology (UMT), Lahore Pakistan; 'Department of \\ Histopathology, Armed Forces Institute of Pathology (AFIP), Pakistan; 'Department of Zoology, University of Gujrat, Gujrat, Pakistan
}

\begin{abstract}
A retrospective study was performed to report the case occurrence of cystic echinococcosis (CE) in three hospitals of north-eastern region in Punjab Province, Pakistan. We reviewed retrospectively the clinical records of patients in 4 hospitals which were diagnosed with CE during 2012-2017. A total of 198 cases, 82 (41.4\%) male and 116 (58.6\%) females were detected as CE. The most Highest incidence was revealed in.... 21-30 years-old group (24.2\%) followed by 41-50 (22.7\%), 31-40 (16.2\%), 11-20 (13.6\%), 51-60 (8.1\%), below 10 (5.5\%), over 71 (5.1\%) and 61-70 year-old group $(4.5 \%)$. CE was detected in various organs of infected individuals. However, most of CE cases were detected in the liver $(47.4 \%)$ and lung (18.6\%). The present study indicated that CE is more or less prevalent in surveyed areas and one of the most important public health problems in Punjab Province, Pakistan.
\end{abstract}

Key words: Cystic echinococcosis, epidemiology, human, Punjab, Pakistan

Echinococcosis is one of the neglected tropical diseases. In human the causative agent of cystic echinococcosis (CE) is larval stage of Echinococcus granulosus. Being zoonotic disease, the life cycle is completed in different hosts. Humans are the accidental host of disease, many herbivores and omnivores are the intermediate hosts while carnivores are the definitive host. Humans are infected due to consumption of contaminated food by the eggs of parasite which later on develop into larval stage in different organs [1]. These visceral organs containing metacestod larvae are then ingested by carnivore hosts and develop in their intestine into mature tapeworm [2]. E. granulosus sensu lato include E. granulosus sensu stricto, E. felidis, E. equinus, E. ortleppi and E. canadensis [3,4].

Echinococcosis is an endemic disease in many areas of the world. Several studies were conducted on the prevalence of hydatidosis in livestock of Pakistan [5,6], whereas, genotypic characterization of E. granulosus has been reported only in Punjab

\footnotetext{
- Received 29 March 2018, revised 2 August 2018, accepted 6 August 2018.

*Corresponding author (ssimsek@firat.edu.tr)

(C) 2018, Korean Society for Parasitology and Tropical Medicine

This is an Open Access article distributed under the terms of the Creative Commons Attribution Non-Commercial License (http://creativecommons.org/licenses/by-nc/4.0) which permits unrestricted non-commercial use, distribution, and reproduction in any medium, provided the original work is properly cited.
}

and Sindh province of Pakistan $[7,8]$. While in recent reports, CE in human was reported in Karachi [9], Hyderabad [10], Peshawar [11], Lahore [12] and studies on molecular genotyping of human echinococcosis are still lacking yet. No comprehensive survey on epidemiology and prevalence of human CE has not been conducted till date [13]. Many researchers reported the incidence of CE in the neighboring countries like China, India, Iran. China holds a high percentage in the global burden of both cystic and alveolar echinococcosis. A national survey conducted between 2012 and 2016 showed that an estimated 50 million people are at risk of contacting the disease in western China, of whom about 0.17 million are cases with CE [14]. Iran is an important endemic region of $\mathrm{CE}$, where there are various species of the intermediate host for E. granulosus. Human CE cases are also routinely documented in medical centers in different parts of Iran and the rate of human infection was 0.61-2/ $1,000,000$ people in various regions $[15,16]$. In Iran average number of surgical CE cases per year was estimated at 1,295 from 2000-2009. The number of asymptomatic individuals living in the country was estimated at $635,232[17,18]$. Previous hospital based studies and case reports revealed that the disease is endemic in many parts of India [19].

Human CE cases in Pakistan need to be reported in near fu- 


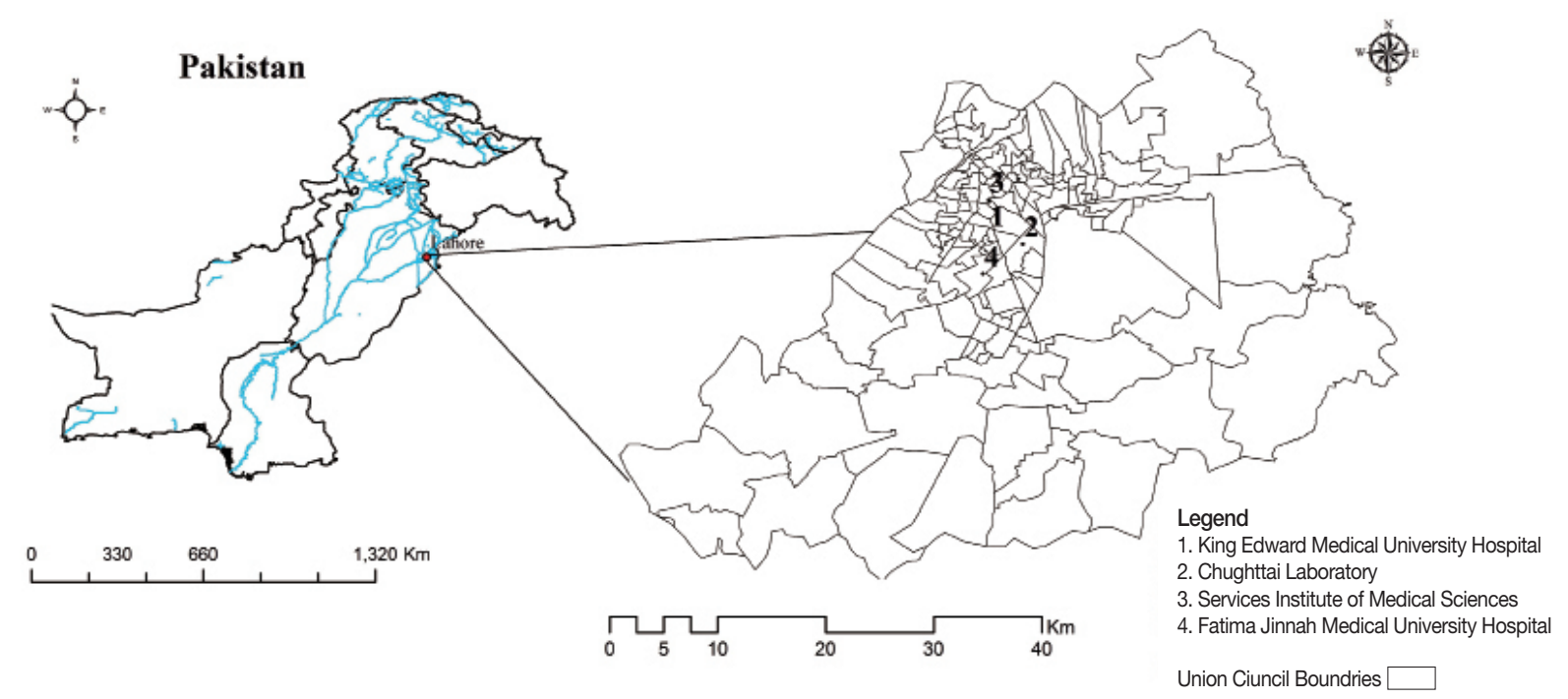

Fig. 1. Map of the study area. (1) King Edward Medical University Hospital. (2) Services Institute of Medical Sciences. (3) Fatima Jinnah Medical University Hospital. (4) Chughttai Laboratory.

ture. A comprehensive study has not been performed on epidemiology and incidence of human CE till date [13]. The aim of the present study was to investigate the retrospective analysis of CE patients in different hospitals of north-eastern region (Lahore) of Punjab province, Pakistan. It will expand further studies on defining risk factors contributing to the disease endemicity in Pakistan.

The present study was conducted in Lahore city of Punjab province, Pakistan. Lahore is situated in the north-eastern part of Pakistan. It is the capital city of Punjab province and is a center of cultural diversity. According to recent census of Pakistan, the population of Lahore is more than 7 million and 42nd most heavily populated city in the world (Fig. 1). The residents make their homes in the 9 administrative towns and one military designated area. It has $40 \%$ of its inhabitants between or below the age of 15 . The average life expectancy stands at less than 60 years. Only $40 \%$ of the population of city is literate [20].

The study area has diverse environmental conditions with temperature exceeding $40^{\circ} \mathrm{C}$ in summers. The summers are extreme and winters are moderate in Lahore [20].

The duration of the study was from January 2012 to December 2017. Main hospitals from the study area were selected for data collection. These hospitals have better facilities for disease diagnosis and are performing pathological examination of cyst samples from nearby areas as well. Human CE cases were retrieved from different hospitals including King Edward Medi- cal University Hospital, Services Institute of Medical Sciences, Fatima Jinnah Medical University Hospital and Chughttai Laboratory. The data used as CE cases in this study were only postoperatively confirmed with histopathological reports. The patient's data was registered, and questionnaires were filled. It consisted of patient's gender, age, while residential city was notified from hospital records. Moreover, histopathological details of cysts were also collected including size, number, nature and localization. Descriptive statistics were calculated for each variable. The chi square $\left(\chi^{2}\right)$ test was used for the mean and standard deviation (SD) for continuous variables. Statistical analysis was performed by using SPSS 16 software (SPSS Inc., Chicago, Illinois, USA) for Windows. The present study is based on confirmed surgically treated CE patients. The permission was granted by respective hospital department. The study was approved by the institutional review board under $\mathrm{ERB} / 18 / 72$.

The retrieval of data from hospital records revealed a total of 198 diagnosed and operated CE cases with an average of 33 cases per year. The highest number of cases $(n=53,26.7 \%)$ was registered in 2015 and the least recorded in $2012(\mathrm{n}=11$, $5.5 \%$ ). In human, cysts take many years to develop within the human body and there might be chances that less number of infected animals were slaughtered at that year in the past. There were less chances for dogs to consume the carcass and the environment was less contaminated with dog faeces having the parasite eggs. It might be one of the reasons in the year 


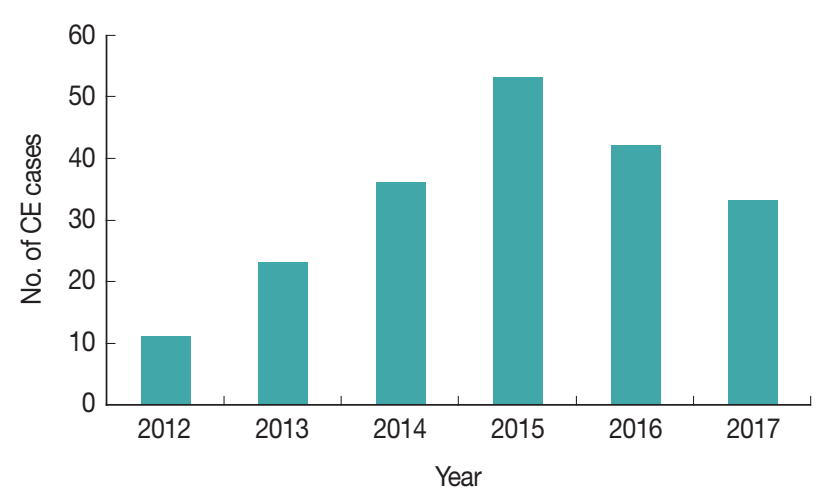

Fig. 2. Year wise cases of human CE cases between 2012-2017.
Table 1. Incidence of CE by the age and sex of positive cases

\begin{tabular}{lccc}
\hline Age (year) & Female (\%) & Male (\%) & Total (\%) \\
\hline Below 10 & $6(54.5)$ & $5(45.4)$ & $11(5.5)^{\mathrm{e}}$ \\
$11-20$ & $9(33.3)$ & $18(66.6)$ & $27(13.6)^{\mathrm{d}}$ \\
$21-30$ & $27(56.2)$ & $21(43.7)$ & $48(24.2)^{\mathrm{a}}$ \\
$31-40$ & $21(65.6)$ & $11(34.4)$ & $32(16.2)^{\mathrm{c}}$ \\
$41-50$ & $31(68.9)$ & $14(31.1)$ & $45(22.7)^{\mathrm{b}}$ \\
$51-60$ & $11(68.7)$ & $5(31.2)$ & $16(8.1)^{\mathrm{e}}$ \\
$61-70$ & $7(77.7)$ & $2(22.2)$ & $9(4.5)^{\mathrm{e}}$ \\
Over 71 & $4(40)$ & $6(60)$ & $10(5.1)^{\mathrm{e}}$ \\
Total & $116(58.6)^{\mathrm{f}}$ & $82(41.4)^{\mathrm{g}}$ & 198 \\
\hline
\end{tabular}

$a, b, c, d, e$ Values with the different letters in the same column are significantly different $\left(\chi^{2}=80.32 ; P<0.001\right)$.

$f, 9$ Values with the different letters in the same line are significantly different $\left(\chi^{2}=11.67 ; P=0.001\right)$.

Table 2. Incidence of CE by the organ in 198 human cases

\begin{tabular}{|c|c|c|c|}
\hline Organs & $\begin{array}{c}\text { No. of CE } \\
(\%)\end{array}$ & Frequency (\%) & $\begin{array}{c}\text { No. of } \\
\text { multiple } \\
\text { cysts }\end{array}$ \\
\hline Liver & $94(47.4)^{\mathrm{a}}$ & $\begin{array}{r}\text { Male } 33(35.1) \\
\text { Female } 61(64.8)\end{array}$ & 9 \\
\hline Lung & $37(18.6)^{b}$ & $\begin{array}{r}\text { Male } 24(64.8) \\
\text { Female } 13(35.1)\end{array}$ & 1 \\
\hline Spleen & $7(3.5)^{d}$ & $\begin{array}{r}\text { Male } 4(57.1) \\
\text { Female } 3(42.8)\end{array}$ & 3 \\
\hline Uterus & $4(2.0)^{d}$ & $4(100)$ & \\
\hline Ovary & $1(0.5)^{d}$ & $1(100)$ & \\
\hline Kidney (Kidney+Right adrenal mass) & $8(3.5)^{d}$ & $8(100)$ & \\
\hline Extremity (Forearm+Pelvis+Femur+Thigh+Erosion of hip+Right lliac bone) & $11(1.0)^{c}$ & $11(100)$ & 1 \\
\hline $\begin{array}{l}\text { Abdominal Cavity (Peritoneum+Mesenterium+Epigastrium+Omentum+Intestinal adhesion+Retroperitonial } \\
\text { space+Abdomen) }\end{array}$ & $11(0.5)^{c}$ & $11(100)$ & \\
\hline Thoracic Cavity (Left thoracic cavity+Subphrenic space+Right Hypochondrium) & $5(0.5)^{d}$ & $5(100)$ & \\
\hline Brain (Left Parietal Lobe+Left Parieto-Occipital Lobe+extradural space AT, D3) & $3(0.5)^{d}$ & $3(100)$ & \\
\hline Lymph Node (Sub-mandibular lymph node) & $1(0.5)^{d}$ & $1(100)$ & \\
\hline Gall bladder & $4(2.0)^{d}$ & $4(100)$ & \\
\hline Upper dorsal cavity & $1(0.5)^{d}$ & $1(100)$ & \\
\hline Site Not Mention & $11(5.5)^{c}$ & $11(100)$ & \\
\hline
\end{tabular}

a,b,c,d, Values with the different letters in the same column are significantly important $\left(\chi^{2}=605.34 ; P<0.001\right)$.

of 2012-2014 with low number of or less positive cases, as compared to 2015 followed by 2016 and 2017, respectively and might be low chances of the people to get infected with CE (Fig. 2). Table 1 predicts the age and gender distribution of the reported cases. Females (58.5\%) were more infected than males $(41.4 \%)\left(\chi^{2}=11.67 ; P=0.001\right)$. The age group of $21-30$ had maximum number of patients $(24.2 \%)$ and in the age group of $61-70(9 \%)$ had less patients $\left(\chi^{2}=80.32 ; P<0.001\right)$. The mean patient age lied in the range of 35 years with 17.4 SD. Table 2 illustrates the localization of cyst administered in the studied hospitals. Liver was the most affected organ in both genders with more frequency seen in females (64.8\%) than males $\left(35.1 \% ; \chi^{2}=1,444.38 ; P<0.001\right)$. Lungs were the second most infected organ (18.6\%). Seven cases of spleen and kidney were recorded. In females 4 uterus and 1 ovarian cases were recorded. The number of registered cases of thigh and gall bladder were same $(n=4,2 \%)$. Three cases of omental mass and right hypochondrium and 2 of epigastrium, pelvis, and mesentery were recorded. Various other atypical organs were also affected which included femur, peritoneum, cranium parietal lobe, parieto-occipital lobe, erosion of hip, sub-mandibular lymph node, right adrenal mass and right iliac bone.

The occurrence of CE contributes to the endemicity of the 
disease. There are approximately 270 million people (58\% of the total population) at risk of CE in Central Asia including areas of Turkmenistan, Kyrgyzstan, Kazakhstan, Mongolia, Tajikistan, Afghanistan, Uzbekistan, Iran, Pakistan and Western China [21]. In Pakistan, human CE has not been explored thus the published data on the disease contain a limited number of case reports in different body organs and 3 prevalence data reports from 1980 to 2015 [13]. The current analysis aimed to review hospital based reported cases of CE from Lahore. Livestock keeping is the occupation of $55.84 \%$ of the population and acts as potential risk factor in the study area [20]. Livestock has a role in transmission of the disease. Dogs feeding on infected organs of slaughtered animals spread the disease in the area. The environmental conditions of the study area and the association of livestock and dogs with carcasses of infected animals may act as potential risk factor for the disease occurrence. Incidence of CE can be measured through hospital based data of diagnosed cases by using the classification as recommended by WHO $[22,23]$. In present retrospective study, human CE cases were investigated from January 2012 to December 2017. The prevalence of E. granulosus infection has been reported to be higher in livestock $[5,6]$. The direct association of growing occurrence of the disease in human needed to be identified in Pakistan since there is lack of any of such information. Human echinococcosis emergence might have resulted due to an increased prevalence of E. granulosus in livestock. The transmission of disease depends on different environmental factors. The migration among rural and urban area inhabitants for raising livestock can also be the reason of disease spread to different areas.

There are certain risk factors responsible for the disease spread including home slaughtering, interaction with livestock, dogs, and poor hygiene. In Pakistan, potential risk factors have been identified via community survey, which showed interaction of $58.1 \%$ of inhabitants with dogs and consumption of contaminated organs by dogs (63\%). Home slaughtering is also practiced commonly by $20.06 \%$ of the inhabitants practice home slaughtering [24]. The route of infection in the present study might be contaminated vegetables/soil from the infected dogs, which feed on infected lungs/liver of livestock animals in the study area. Similar studies on risk factors showed $14.7 \%$ of infected stray dogs with no veterinary care wander freely in living area and interact with human as well as their livestock thus maintaining the CE cycle which spreads the disease in area and $80 \%$ infestation rate of dogs in abattoir surroundings were predicted due to consumption of infected hydatid cyst containing organs $[25,26]$.

In the present study age distribution showed that the highest number of infected individuals lied in 21-30 years. Similar retrospective studies in Iraq showed high rate same higher rate of infection among 21 to 30 years age group [27]. the mean affected age in current study was 35+-17. The average affected age varies with the variations in study area. The mean age of 40 years was also showed to be mostly affected in Chile [28]. Similarly mean age of 40 year was reported in Turkey [29]. There were $19.1 \%$ cases reported below 20 years of age in the present study while a study performed in Egypt showed one third of reported cases under the age of 20 years [30]. In the current analysis, gender distribution of CE was studied based on hospitalization records and it revealed that females (58.5\%) acquired more disease than males. Similar findings were reported in Iraq [27] and Iran [16]. The probable reason for this can be increased interaction to potential risk factors including livestock management and poor living hygenic conditions. Based on our collected hospital data, cyst localization was very diverse. The highest number of cysts was recorded in liver (47.4\%) followed by lungs (18.6\%). were more affected. Similar results were reported in most of the retrospective studies [28,31].

In the present study, most of the recorded cases contained single cyst involvement while few multiple cysts were also observed in agreement to a study conducted in Iraq [27]. Cyst development at unusual sites was also observed (28.2\%). These sites included omentum, kidney, adrenal mass, spleen, gall bladder, uterus, forearm, epigastrium, pelvis, femur, peritoneum, mesentery, thigh, left parietal lobe, parieto-occipital lobe, erosion of hip, sub-mandibular lymph node, and right iliac bone. Similar findings in unusual sites were also reported in Turkey [29].

Cystic echinococcosis can be prevented by increasing awareness about the disease as reported earlier in a study that a very small proportion of individuals had knowledge of hydatidosis or zoonosis; even lesser percentage (4.1\%) of associated individuals had ever heard about the disease [24]. Moreover, there is need for comprehensive study on the disease so that control and prevention strategies can be developed. Lack of significant data on echinococcosis pushes it towards the future research domain for generating data on epidemiology of the disease and genetic diversity of the infectious agent. Being a neglected disease in Pakistan, limited work has been done on the dis- 
ease although $\mathrm{WHO}$ commensurate this disease to be of significant concern to public health [23].

It is concluded from the present study that CE is prevalent in the surveyed areas and this endemic disease is to be the public health problems in Punjab Province, Pakistan. Although very limited studies are performed on echinococcosis, a remarkable increase in incidence of cystic echinococcosis reported cases was observed in current study in different years which draws attention towards the emerging trend of the disease. It is a continuous threat to public health due to its zoonotic mode. In Pakistan, this zoonosis has been expected to be encountered frequently despite of continuous negligence to the disease. The hospital data recorded all symptomatic cases while the disease may remain asymptomatic for many years and is underrepresented and misdiagnosed, so higher incidence is presumed and can be confirmed through future research and development of proper surveillance system on the disease. Thus, in the present analysis, regional data publication may assist in devising control and treatment strategies.

\section{ACKNOWLEGMENT}

We are very thankful to all participated hospitals from Punjab Province, Pakistan for their cooperation in the data collection.

\section{CONFLICT OF INTEREST}

The authors fully declare any financial or other potential conflict of interest.

\section{REFERENCES}

1. Eckert J, Deplazes P. Biological, epidemiological, and clinical aspects of echinococcosis, a zoonosis of increasing concern. Clin Microbiol Rev 2004; 17: 107-135.

2. Budke CM, Deplazes P, Torgerson PR. Global socioeconomic impact of cystic echinococcosis. Emerg Infect Dis 2006; 12: 296303.

3. Nakao M, McManus DP, Schantz PM, Craig PS, Ito A. A molecular phylogeny of the genus Echinococcus inferred from complete mitochondrial genomes. Parasitology 2006; 134: 713-722.

4. Hüttner M, Nakao M, Wassermann T, Siefert L, Boomker JD, Dinkel A, Sako Y, Mackenstedt U, Romig T, Ito A. Genetic characterization and phylogenetic position of Echinococcus felidis Ortlepp, 1937 (Cestoda: Taeniidae) from the African lion. Int J Parasitol 2008; 38: 861-868.

5. Tasawar Z, Naz F, Lashari MH. The prevalence of hydatidosis in sheep and buffaloes at Multan, Punjab, Pakistan. Global Veterinaria $2015 ; 12: 332-335$.

6. Mustafa I, Shahbaz M, Asif S, Khan MR, Saeed U, Sadiq F, Mehmood T, Ahmed H, Simsek S. Availability, cyst characteristics and hook morphology of Echinococcus granulosus isolates from livestock (cattle, sheep and goats) in central Punjab, Pakistan. Kafkas Univ Vet Fak Derg 2015; 21: 849-854.

7. Shahzad W, Abbas A, Munir R, Khan MS, Avais M, Ahmad J, Rana MY, Mehmood F. A PCR analysis of prevalence of Echinococcus granulosus genotype G1 in small and large ruminants in three districts of Punjab, Pakistan. Pakistan J Zool 2014; 46: 1541-1544.

8. Ehsan M, Akhter N, Bhutto B, Arijo A, Ali Gadahi J. Prevalence and genotypic characterization of bovine Echinococcus granulosus isolates by using cytochrome oxidase 1 (CO1) gene in Hyderabad, Pakistan. Vet Parasitol 2017; 239: 80-85.

9. Mumtaz K, Kamani L, Chawla T, Hamid S, Jafri W. Hepatic cystic echinococcosis: clinical characteristics and outcomes in Pakistan. Trop Doct 2009; 39: 215-217.

10. Gadahi JA, Bhutto B, Arlio AG, Akhter N. Human hydatidosis in Hyderabad, Sindh-Pakistan. Adv Trop Med Pub Health Int 2011; 1: 90-94.

11. Alam S, Umer US, Gul S, Ghaus S, Farooq B, Gul F. Uncommon sites of a common disease--Hydatid cyst. J Postgrad Med Inst 2014; 28: $270-276$.

12. Ali SA, Akhtar T, Zaki MA, Safi WA. Echinococcosis is an emerging public health problem in Pakistan. Int J Med Pharmaceut Sci 2013; 3: 39-48.

13. Ahmed H, Ali S, Afzal MS, Khan AA, Raza H, Shah ZH, Simsek S. Why more research needs to be done on echinococcosis in Pakistan. Infect Dis Poverty 2017; 6: 90.

14. Qian MB, Abela-Ridder B, Wu WP, Zhou XN. Combating echinococcosis in China: strengthening the research and development. Infect Dis Poverty 2017; 6: 161.

15. Rokni M. Echinococcosis/hydatidosis in Iran. Iran J Parasitol 2009; 4: 1-16.

16. Hajipirloo HM, Bozorgomid A, Alinia T, Tappeh KhH, Mahmodlou R. Human cystic echinococcosis in West Azerbaijan, Northwest Iran: a retrospective hospital-based survey from 2000 to 2009. Iran J Parasitol 2013; 8: 323-326.

17. Fasihi Harandi M, Budke CM, Rostami S. The monetary burden of cystic echinococcosis in Iran. PLoS Negl Trop Dis 2012; 6: e1915.

18. Malik AA, Bari SU, Amin R, Jan M. Surgical management of complicated hydatid cysts of the liver. World J Gastrointest Surg 2010; 2: 78-84.

19. Akther J, Khanam N, Rao S. Clinico epidemiological profile of hydatid diseases in central India, a retrospective and prospective study. Int J Biol Med Res 2011; 2: 603-606.

20. Ministry of Finance, Government of Pakistan. GOP, 2018 Anonymous: Pakistan Economic Survey (2017-18).

21. Zhang W, Zhang Z, Wu W, Shi B, Li J, Zhou X, Wen H, McManus DP. Epidemiology and control of echinococcosis in central Asia, with particular reference to the People's Republic of China. Acta Trop 2015; 141: 235-243. 
22. Eckert J, Gemmell MA, Soulsby EJL. FAO/UNEP/WHO Guidelines for Surveillance, Prevention and Control of Echinococcosis Hydatidosis. Geneva, Switzerland. WHO. 1981.

23. WHO. Factsheets of Echinococcosis. [Internet]; Available from: http://www.who.int/mediacentre/factsheets/fs377/en.

24. Khan A, Naz K, Ahmed H, Simsek S, Afzal MS, Haider W, Ahmad SS, Farrakh S, Weiping W, Yayi G. Knowledge, attitudes and practices related to cystic echinococcosis endemicity in Pakistan. Infect Dis Poverty 2018; 7: 4.

25. Maktoof AR, Abu Tabeekh MAS. Classification of endemicity of cystic echinococcosis in Basrah governorate-Iraq. Savant J Agric Res 2015; 1: 6-9.

26. Acosta-Jamett G, Cleaveland S, Bronsvoort BM, Cunningham AA, Bradshaw H, Craig PS. Echinococcus granulosus infection in domestic dogs in urban and rural areas of the Coquimbo region, northcentral Chile. Vet Parasitol 2010; 169: 117-122.
27. Abdulhameed MF, Habib I, Al-Azizz SA, Robertson I. A retrospective study of human cystic echinococcosis in Basrah province, Iraq. Acta Trop 2018; 178: 130-133.

28. Colombe S, Togami E, Gelaw F, Antillon M, Fuentes R, Weinberger DM. Trends and correlates of cystic echinococcosis in Chile: 2001-2012. PLoS Negl Trop Dis 2017; 11: e0005911.

29. Türkoğlu E, Demirtürk N, Tünay H, Akıc M, Öz G, Baskin Embleton D. Evaluation of patients with cystic echinococcosis. Turkiye Parazitol Derg 2017; 41: 28-33.

30. Kandeel A, Ahmed ES, Helmy H, El Setouhy M, Craig PS, Ramzy RM. A retrospective hospital study of human cystic echinococcosis in Egypt. East Mediterr Health J 2004; 10: 349-357.

31. Zhang T, Zhao W, Yang D, Piao D, Huang S, Mi Y, Zhao X, Cao J, Shen Y, Zhang W, Liu A. Human cystic echinococcosis in Heilongiiang Province, China: a retrospective study. BMC Gastroenterol 2015; 15: 29. 